\title{
O RESSURGIMENTO DA QUÍMICA DE BENZINO COM SILILARIL TRIFLATOS NO CONTEXTO DAS REAÇÕES DE INSERÇÃO EM LIGAÇÕES SIGMA
}

Rafael D. C. Gallo, Hellenicy V. Rezende, Rozanna M. Muzzi e Cristiano Raminelli*

Faculdade de Ciências Exatas e Tecnologia, Universidade Federal da Grande Dourados, Rodovia Dourados-Itahum, km 12, 79804-970 Dourados - MS, Brasil

Recebido em 6/2/09; aceito em 19/6/09; publicado na web em 19/11/09

THE BENZYNE CHEMISTRY REVIVAL WITH SILYLARYL TRIFLATES IN THE CONTEXT OF INSERTION REACTIONS INTO SIGMA BONDS. In this paper we gathered articles concerning insertion reactions of arynes, exclusively generated from 2-(trimethylsilyl)aryl triflates in the presence of fluoride ions, in substrates bearing nucleophilic and electrophilic portions separated by sigma bonds. Accordingly, we stand out the great importance and versatility of such transformations in the preparation of highly functionalized aromatic systems, which are hardly synthesized in just one step for other methods.

Keywords: benzyne; silylaryl triflates; insertion reactions.

\section{INTRODUÇÃO}

Devido à grande importância de benzino (1) como intermediário altamente reativo em química orgânica, com aplicações que permeiam sínteses totais e preparações de materiais funcionais, ${ }^{1}$ um amplo arsenal de métodos empregados na sua formação encontra-se à disposição na literatura. ${ }^{1-6}$ No entanto, vale destacar que os métodos tradicionais para geração de arinos, embora em posição de destaque no contexto da química de benzino, ${ }^{1}$ inviabilizavam muitas das aplicações de tais espécies reativas no universo da química orgânica, devido às condições reacionais drásticas utilizadas, incluindo altas temperaturas, reagentes extremamente básicos ou fortemente oxidantes. ${ }^{1-6}$

Em virtude do cenário delineado, Kobayashi e colaboradores publicaram no início da década de 80 , uma rota sintética para a obtenção de 2-(trimetilsilil)fenil triflato (2), que foi usado na formação de benzino (1) sob condições reacionais brandas, que envolvem o uso de uma fonte de íons fluoreto, um solvente polar aprótico e temperaturas próximas da temperatura ambiente ${ }^{7}$ (Esquema 1).

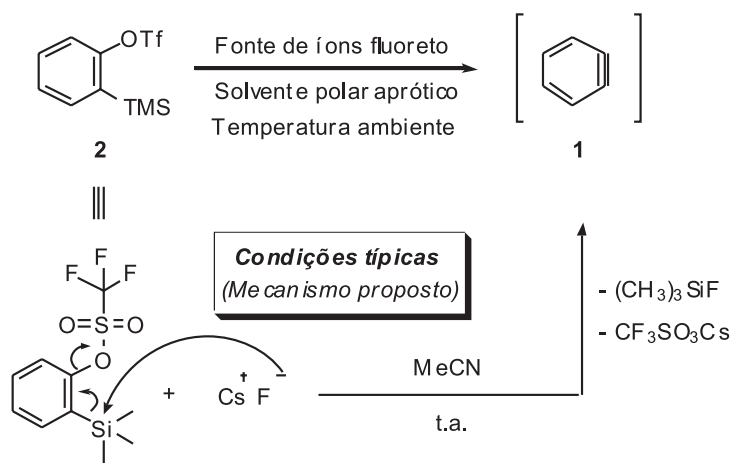

Esquema 1. Formação de benzino a partir de 2-(trimetilsilil)-fenil triflato

Embora o emprego das condições brandas apresentadas no Esquema 1 possa ser considerado um enorme avanço para a química de benzino, tal metodologia permaneceu adormecida até o final do século XX, quando Guitián e colaboradores empregaram 2-(trimetilsilil) fenil triflato na preparação de benzo $[a]$ pireno. ${ }^{8}$ Vale mencionar que

*e-mail: raminelli@ufgd.edu.br posteriormente, Guitián, Pérez e colaboradores deram outra enorme contribuição para a química de benzino, publicando trabalho pioneiro que estabeleceu a utilização de arinos formados a partir de 2-(trimetilsilil)aril triflatos, em reações catalisadas por metais de transição. ${ }^{9}$

Entretanto, foi somente no início do século XXI que Shirakawa, Hiyama e colaboradores publicaram os primeiros trabalhos fazendo uso de 2-(trimetilsilil)aril triflatos em reações de inserção em ligações sigma. ${ }^{10,11}$ Desde então, o desenvolvimento de metodologias sintéticas para preparação de sililaril triflatos experimentou uma grande evolução ${ }^{12}$ e, atualmente, 2-(trimetilsilil)fenil triflato é um reagente comercialmente disponível. Estes acontecimentos refletiram no desenvolvimento de inúmeras reações de inserção em ligações sigma fazendo uso de arinos gerados a partir de sililaril triflatos, ${ }^{13}$ as quais ocorrem em compostos que apresentam uma porção nucleofílica e outra eletrofílica, unidas por uma ligação simples. Em conformidade, vale destacar que na prática, tais reações podem ocorrer por mecanismo delineado no Esquema 2, bem como na presença de quantidades catalíticas de paládio, pelos ciclos catalíticos apresentados no Esquema 3.

Por causa do caráter altamente eletrofílico de arinos, resultado de seus LUMOs de baixa energia, até mesmo nucleófilos de baixa nucleofilicidade atacam facilmente benzino e seus derivados produzindo espécies zwiteriônicas, que atuam como intermediários chaves nas reações de inserção em ligações sigma ${ }^{11,14}$ (Esquema 2).

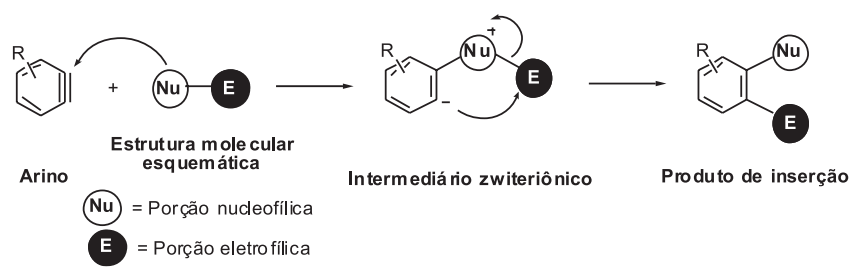

Esquema 2. Mecanismo proposto para a inserção de arinos a ligações sigma

Em linha com o comportamento de arinos em reações catalisadas por metais de transição ${ }^{9}$ e levando em consideração dados experimentais, ${ }^{10}$ os ciclos catalíticos A e B devem ser considerados. Desta maneira, voltando nossa atenção para o ciclo catalítico A, observamos a adição oxidativa do composto M-X à espécie de paládio (0) ativa no ciclo catalítico $\left(\mathrm{Pd}^{\circ}\right)$, resultando no inter- 
mediário I. Este intermediário ao reagir com o arino gerado no meio reacional, produz os intermediários II ou III. Por reação de eliminação redutiva a partir dos intermediários II ou III, vemos a regeneração da espécie de paládio (0) ativa no ciclo catalítico e a formação do produto de inserção. No ciclo catalítico B, inicialmente observamos a complexação do arino formado no meio reacional com a espécie de paládio (0) ativa no ciclo catalítico $\left(\mathrm{Pd}^{\circ}\right)$, resultando no intermediário representado pelas estruturas IV ou $\mathbf{V}$. Tal intermediário reage com o composto $\mathrm{M}-\mathrm{X}$ produzindo os intermediários II ou III. Por reação de eliminação redutiva a partir dos intermediários II ou III, vemos a regeneração da espécie de paládio (0) ativa no ciclo catalítico e a formação do produto de inserção. ${ }^{9,10}$

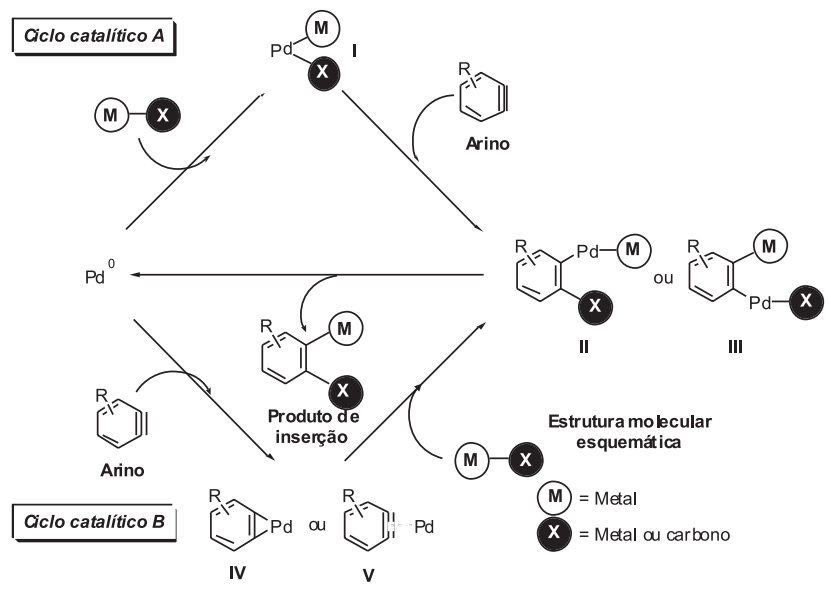

Esquema 3. Ciclos catalíticos propostos para a inserção de arinos a ligações sigma fazendo uso de paládio como catalisador

Neste artigo pretendemos reunir os trabalhos envolvendo reações de inserção de arinos gerados a partir de 2-(trimetilsilil)aril triflatos, em substratos contendo uma porção nucleofílica e outra eletrofílica separadas por uma ligação sigma. Aproveitamos também para destacar a importância e a versatilidade de tais transformações na preparação de sistemas aromáticos, altamente funcionalizados e dificilmente preparados por métodos convencionais, cuja importância em síntese orgânica é indiscutível.

\section{REAÇÕES DE INSERÇÃO DE ARINOS A LIGAÇÕES SIGMA}

Conforme mencionado anteriormente, o primeiro trabalho fazendo uso de sililaril triflatos em reações de inserção em ligações sigma foi publicado por Shirakawa, Hiyama e colaboradores. ${ }^{11}$ Tal trabalho consistiu na adição de arinos formados a partir de 2-(trimetilsilil)aril triflatos (3) na presença de $\mathrm{CsF}$, em ligações sigma $\mathrm{N}-\mathrm{CO}$ de ureias (4), as quais foram empregadas em excesso, resultando na formação de compostos nitrogenados (5) em rendimentos consideráveis (Esquema 4).<smiles>CS(=O)(=O)c1c(Br)ccc2ccccc12</smiles>

3

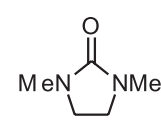

4

excesso

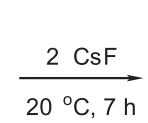<smiles></smiles>
$89 \%$
Esquema 4. Síntese da benzodiazepinona 5 por reação entre 1-(trimetilsilil)2-naftil triflato (3) e 1,3-dimetil-2-imidazolidinona (4) na presença de CsF
A reação de inserção delineada no Esquema 4 mostrou-se altamente regiosseletiva, resultando exclusivamente na benzodiazepinona 5. Em conformidade, esta reação foi empregada na preparação de diversos derivados 1,4-benzodiazepínicos, que constituem um importante grupo de agentes terapêuticos, dentre os quais, mencionamos diazepam e fluorazepam, empregados como ansiolíticos, sedativos, anticonvulsivantes e hipnóticos. Tal reação também foi empregada na obtenção de sistemas 1,5-benzodiazocínicos, que tem atraído muito interesse por serem homólogos de fármacos 1,4-benzodiazepínicos. Vale mencionar que alguns dos heterocíclicos nitrogenados obtidos, exibiram florescência comparável à dos derivados do ácido antranílico, que são sabidamente fluoróforos. ${ }^{11}$

Posteriormente, Yoshida, Kunai e colaboradores exploraram a reação entre 2-(trimetilsilil)aril triflatos (2) e trialquil(ariltio)estananas (6) na presença de KF e éter 18-coroa-6, produzindo trialquil[2(ariltio)aril]estananas (7) em rendimentos moderados ${ }^{15}$ (Esquema 5).

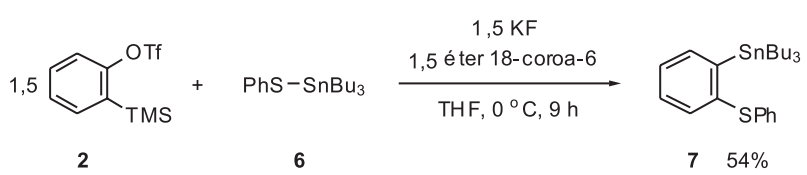

Esquema 5. Síntese da tributil[2-(feniltio)fenil]estanana (7) por reação entre 2-(trimetilsilil)fenil triflato (2) e tributil(feniltio)estanana (6) na presença do sitema KF/éter 18-coroa-6

A versatilidade sintética dos produtos de tioestanilação produzidos foi avaliada aplicando a tributil[2-(feniltio)fenil]estanana (7) na síntese de diversos sistemas aromáticos (8-10), obtidos por reações de acoplamento cruzado (8), de iodólise (9) e de homoacoplamento (10), fazendo uso de condições reacionais descritas na literatura ${ }^{15}$ (Esquema 6).

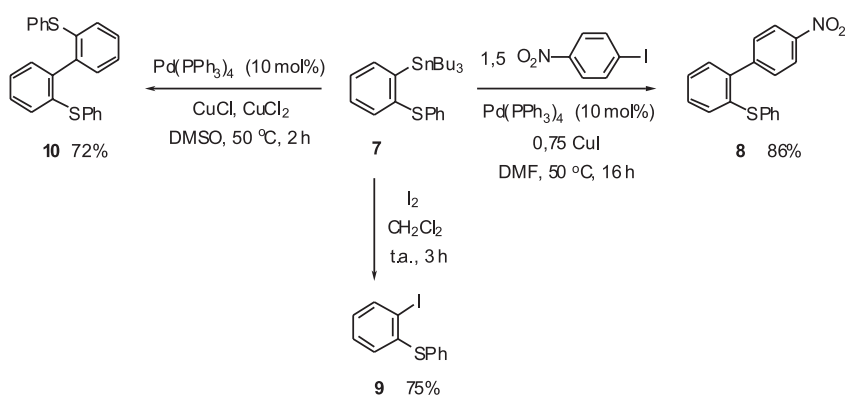

Esquema 6. Síntese dos sistemas aromáticos (8-10) fazendo uso da tributil[2(feniltio)fenil]estanana (7), por meio de reações de acoplamento cruzado (8), de iodólise (9) e de homoacoplamento (10)

Yoshida, Kunai e colaboradores dando continuidade a suas pesquisas envolvendo reações de inserção a ligações sigma, implementaram a reação de adição de arinos formados a partir de 2-(trimetilsilil)aril triflatos (2) na presença de KF e éter 18-coroa-6, em ligações sigma $\mathrm{N}-\mathrm{Si}$ de aminossilanos (11), resultando na formação de compostos aminossililados (12) em bons rendimentos $^{16}$ (Esquema 7).

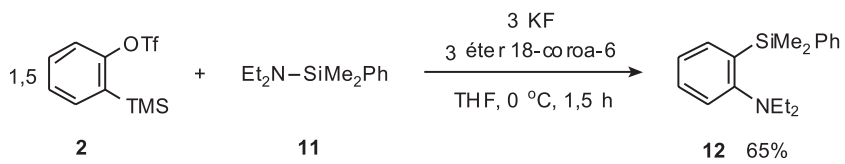

Esquema 7. Síntese da $N, N$-dietil-2-(dimetilfenilsilil)anilina (12) por reação entre 2-(trimetilsilil)fenil triflato (2) e (dietilamino)dimetilfenilsilano (11) na presença de KF e éter 18-coroa-6 
A reação de aminossililação delineada no Esquema 7 foi empregada na síntese do bis(2-aminofenil)silano 14 e na síntese da $N, N^{\prime}$-bis(2sililfenil)piperazina $16 \mathrm{em}$ rendimentos $\operatorname{moderados}^{16}$ (Esquema 8).

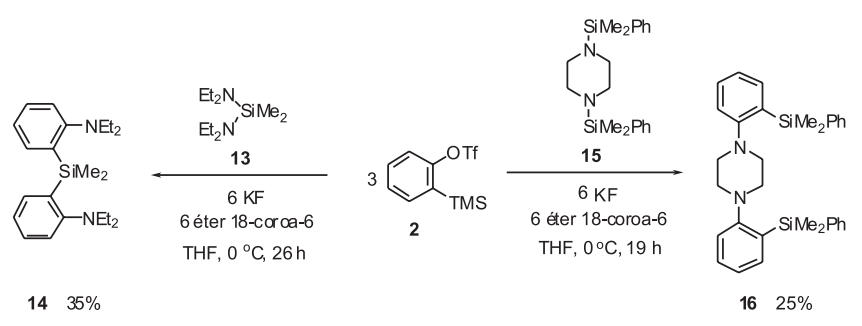

Esquema 8. Reação entre aminossilanos possuindo dois sítios reacionais (13 e 15) e 2-(trimetilsilil)fenil triflato (2) na presença de KF e éter 18-coroa-6

Em linha com os trabalhos apresentados até o momento, Stoltz e colaboradores publicaram a inserção de sililaril triflatos (2) em $\beta$-cetoésteres (17) na presença de CsF em acetonitrila, resultando na formação de compostos aromáticos acil-alquilados (18) em ótimos rendimentos ${ }^{17}$ (Esquema 9).

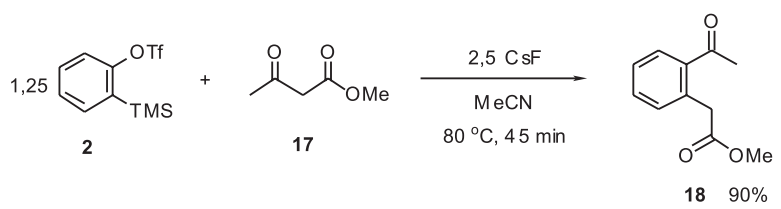

Esquema 9. Síntese de 2-(2-acetilfenil)acetato de metila (18) por reação entre 2-(trimetilsilil)fenil triflato (2) e acetoacetato de metila (17) na presença de Cs

A transformação delineada no Esquema 9, que promove a formação de duas novas ligações $\mathrm{C}$-C pela inserção de um arino em uma ligação simples $\alpha, \beta$ de um $\beta$-cetoéster, representa um interessante método para a preparação de compostos aromáticos substituídos, bem como para a síntese de sistemas carbocíclicos. ${ }^{17}$ Em conformidade, tal reação publicada por Stoltz e colaboradores encontrou aplicação na síntese da (+)-amurensinina ${ }^{18}$ (Esquema 10).
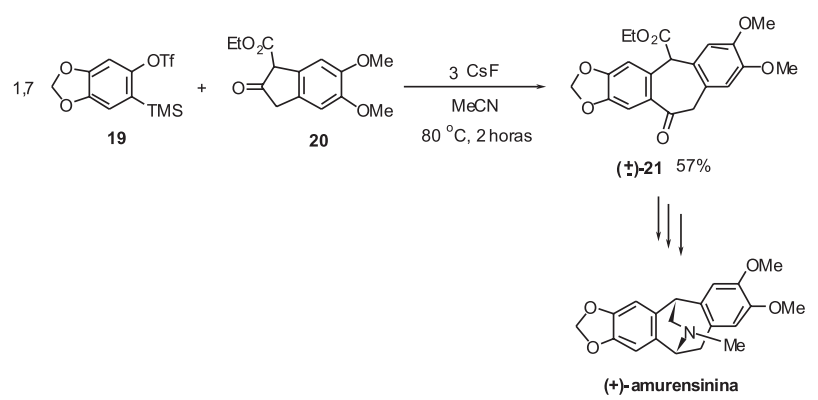

Esquema 10. Reação de inserção entre o sililaril triflato 19 e o $\beta$-dicarbonílico cíclico 20, na preparação do intermediário carbocí clico (士)-21, empregado na sintese da (+)-amurensinina

Vale mencionar que a (+)-amurensinina faz parte de uma família de alcaloides constituída pelas isopavinas, as quais apresentam importantes propriedades no tratamento de desordens neurológicas, tais como o mal de Parkinson e o mal de Alzheimer. ${ }^{18}$

Pouco tempo depois do trabalho pioneiro de Stoltz e colaboradores ter sido publicado (Esquema 9), Yoshida, Kunai e colaboradores reportaram uma reação similar de inserção de sililaril triflatos em compostos $\beta$-dicarbonílicos na presença do sistema KF/éter 18-coroa-6, resultando na formação de compostos aromáticos orto-substituídos.
Esta reação ao contrário daquela desenvolvida por Stoltz e colaboradores pode ser realizada à temperatura ambiente. ${ }^{19}$

Visando explorar a inserção de arinos em compostos com grupos metileno ativos, Yoshida, Kunai e colaboradores submeteram 2-(trimetilsilil)aril triflatos (22) à reação com compostos $\alpha$-cianocarbonílicos (23) na presença de KF e éter 18-coroa-6, resultando na formação de sistemas aromáticos orto-substituídos com grupos carbonila e cianometila (24) em rendimentos consideráveis $^{20}$ (Esquema 11).

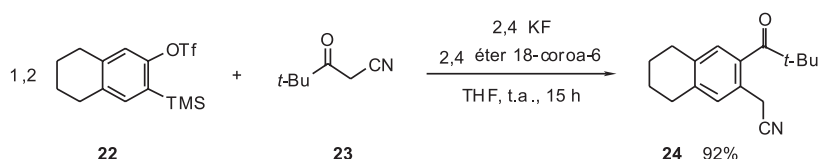

Esquema 11. Síntese do composto aromático orto-substituído 24 fazendo uso do sililaril triflato 22 e do composto $\alpha$-cianocarbonílico 23 na presença de KF e éter 18-coroa-6

Em linha com os resultados delineados no Esquema 11 apresentamos a reação entre 2-(trimetilsilil)aril triflatos (2) e $\alpha$-cianometildifenilfosfinóxido (25) na presença de KF e éter 18-coroa-6, resultando na formação de compostos aromáticos ortosubstituídos com grupos difenilfosfinóxido e cianometila (26) em rendimentos moderados ${ }^{21}$ (Esquema 12).

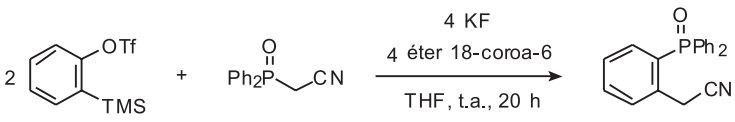

$$
\begin{aligned}
& 25
\end{aligned}
$$

Esquema 12. Síntese do composto aromático orto-substituído 26 fazendo uso de 2-(trimetilsilil)fenil triflato (2) e de $\alpha$-cianometildifenilfosfinóxido (25) na presença de KF e éter 18-coroa-6

Larock e colaborador deram a sua contribuição com relação à inserção de arinos em ligações sigma C-N e S-N, publicando trabalho que reuniu a adição de sililaril triflatos (2) a $N$-ariltrifluoroacetamidas (27) (Esquema 13), bem como a adição de sililaril triflatos (2) a trifluorometanossulfonamidas (29) (Esquema 14), em ambos os casos fazendo uso de uma fonte de íons fluoreto. ${ }^{22}$

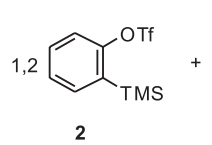

2

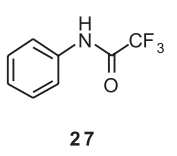

27
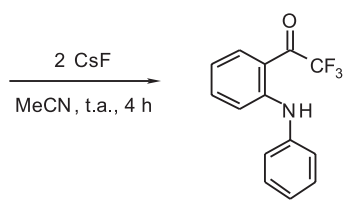

$2877 \%$
Esquema 13. Sintese do composto aromático orto-substituído 28 fazendo uso do sililaril triflato 2 e da $\mathrm{N}$-ariltrifluoroacetamida 27 na presença de CsF em acetonitrila

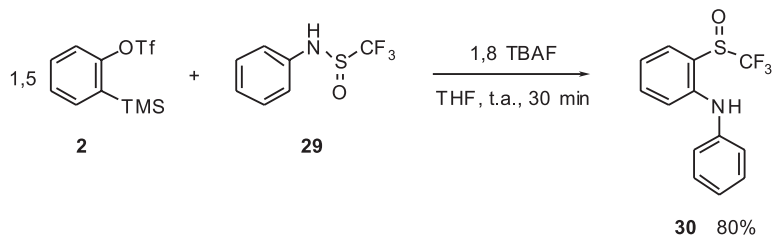

Esquema 14. Síntese do composto aromático orto-substituído 30 fazendo uso do sililaril triflato 2 e da trifluorometanossulfonamida 29 na presença de fluoreto de tetrabutilamônio (TBAF) em THF 
Vale destacar que a preparação dos compostos aromáticos ortosubstituídos 30 (Esquema 14), só foi possível em rendimentos consideráveis, quando TBAF foi empregado em THF a temperatura ambiente. ${ }^{22}$ Adicionalmente, as reações apresentadas nos Esquemas 13 e 14 constituem novos métodos para a inserção de arinos em ligações C-N e S-N na ausência de metais de transição e em condições reacionais brandas. ${ }^{22}$

Na tentativa de evidenciar o enorme potencial sintético das reações de inserção de arinos a ligações sigma, apresentamos o trabalho de Huang e colaborador que trata da reação multicomponente entre um sililaril triflato (2), uma sulfona (31) e um aceptor de Michael (32), fazendo uso de $\mathrm{NaH}, \mathrm{KF}$ e éter 18-coroa-6, na formação de derivados do naftol (33) em rendimentos consideráveis, por meio de mecanismo possivelmente envolvendo a formação de arinos (1), enolatos (38), bem como outros possíveis intermediários (34-37) ${ }^{23}$ apresentados no Esquema 15.

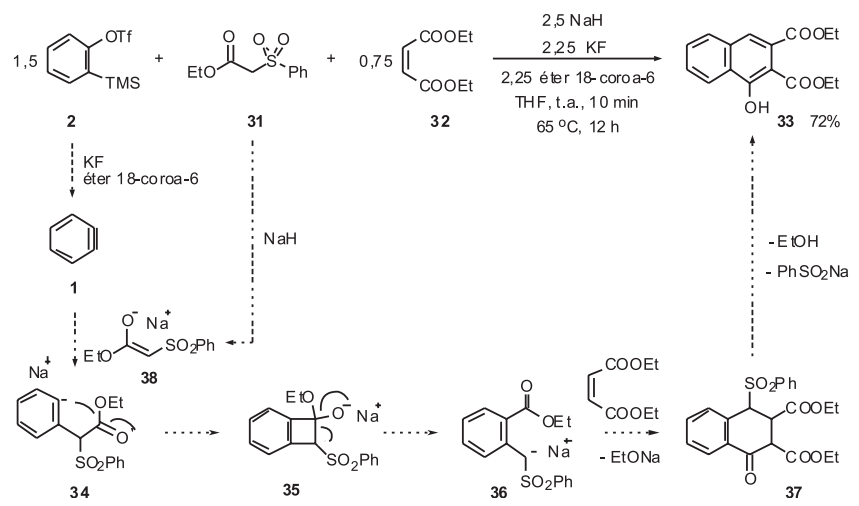

Esquema 15. Síntese de derivado do naftol (33) por reação de três componentes envolvendo benzino (1)

O possível mecanismo apresentado no Esquema 15 para a reação multicomponente envolvendo arinos foi proposto com base na sequência de experimentos delineados nos Esquemas 16 e 17.
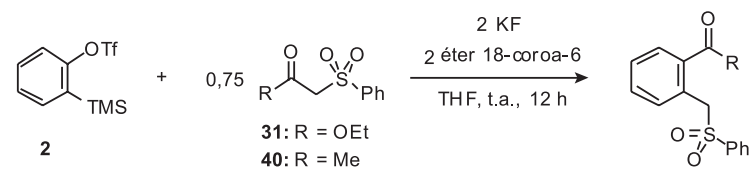

39: $\mathrm{R}=\mathrm{OEt} ; 85 \%$ 41: $\mathrm{R}=\mathrm{Me} ; 81 \%$

Esquema 16. Reação entre 2-(trimetilsilil)fenil triflato (2) e as sulfonas 31 e 40 na presença de KF e éter 18-coroa-6, resultando na formação dos compostos aromáticos orto-substituídos 39 e 41, respectivamente

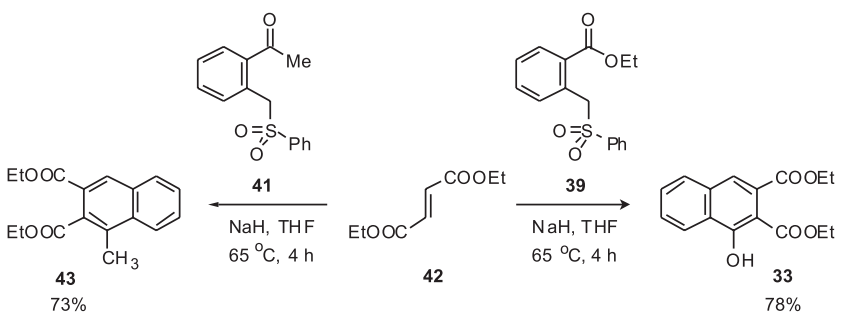

Esquema 17. Reação das sulfonas 39 e 41 com fumarato de dietila (42), na presença de $\mathrm{NaH}$, resultando na formação de derivados do naftol (33) e do naftaleno (43), respectivamente

As reações delineadas nos Esquemas 16 e 17 podem justificar a proposição do mecanismo mostrado no Esquema 15. No entanto, vale mencionar que os intermediários apresentados no Esquema 15 não foram detectados e muito menos isolados até o presente momento.

Voltando nossa atenção para a reação delineada no Esquema 16, devemos relatar que um estudo complementar envolvendo a reação de inserção de arinos em $\beta$-cetossulfonas foi posteriormente publicado por Huang e colaboradores. ${ }^{24}$

Adicionalmente, Hu e colaboradores em um volumoso e denso manuscrito, que racionaliza a natureza dura/macia de carbânions fluorados, apresentam a reação de adição de arinos formados a partir de 2-(trimetilsilil)aril triflatos (2) na presença de CsF, em ligação sigma C-C de 2-fluoro-2-(fenilsulfonil)acetofenona (44), resultando na formação de compostos aromáticos orto-substituídos 45 em excelentes rendimentos ${ }^{25}$ (Esquema 18).

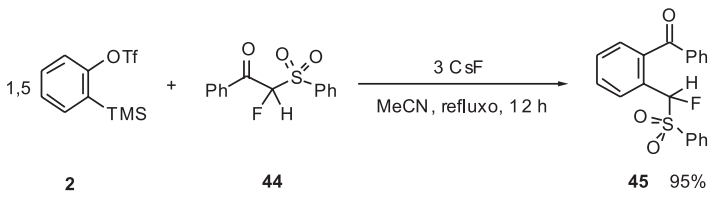

Esquema 18. Síntese do composto aromático orto-substituído 45 por reação entre 2-(trimetilsilil)fenil triflato (2) e 2-fluoro-2-(fenilsulfonil)acetofenona (44) na presença de $C s F$

A transformação apresentada no Esquema 18 pode ser considerada como uma valiosa contribuição para a química de benzino, quando vista como a primeira reação entre um arino e um carbono nucleofílico possuindo um átomo de fluor. ${ }^{25}$

Visando a reação de inserção de arinos a ligações C-O de epóxidos, Peña e colaboradores deixaram 2-(trimetilsilil)fenil triflato (2) reagir com óxido de extireno (46) na presença de CsF, produzindo 2,3-di-hidro-3-fenilbenzofurano (47) em rendimento moderado (Esquema 19). ${ }^{26}$

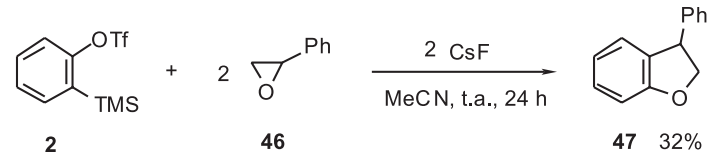

Esquema 19. Síntese do 2,3-di-hidro-3-fenilbenzofurano (47) por reação entre 2-(trimetilsilil)fenil triflato (2) éxido de extireno (46) na presença de CsF

Embora as condições reacionais apresentadas no Esquema 19 não tenham sido otimizadas no sentido de tornar a reação interessante do ponto de vista sintético, a mesma consiste no primeiro exemplo de inserção de arinos em ligações sigma de moléculas cíclicas com alta tensão de anel. ${ }^{26}$

Yoshida, Kunai e colaboradores na busca por uma metodologia para acilação orto-seletiva de haloarenos, realizaram a reação entre 2-(trimetilsilil)aril triflatos (2) e haletos de ácidos (48) na presença de KF e éter 18-coroa-6, produzindo arilcetonas 2-halossubstituídas (49) em bons rendimentos ${ }^{27}$ (Esquema 20).

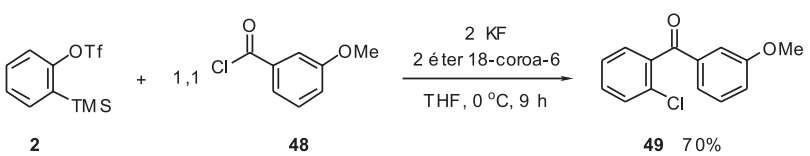

Esquema 20. Síntese da 2-cloro-3'-metoxibenzofenona (49) por reação entre 2-(trimetilsilil)fenil triflato (2) e cloreto de 3-metoxibenzoíla (48) na presença de KF e éter 18-coroa-6

Pela reação mostrada no Esquema 20, arilcetonas 2-halogenadas, cuja síntese regiosseletiva pela acilação convencional de Friedel- 
Crafts seria pouco provável, podem ser produzidas de maneira direta em rendimentos satisfatórios. ${ }^{27}$

Em nosso trabalho envolvendo a inserção de arinos em diorgano dicalcogenetos em condições reacionais brandas, 2-(trimetilsilil)fenil triflato (2) e diorgano dicalcogenetos (50) foram deixados reagir na presença de CsF, resultando em 1,2-bis(organilcalcogenil)benzenos (51) em rendimentos que variaram de moderados a bons ${ }^{28}$ (Esquema 21).

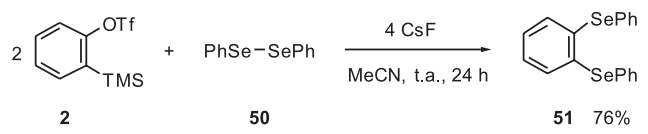

Esquema 21. Síntese do 1,2-bis(fenilselenil)benzeno (51) por reação entre 2-(trimetilsilil)fenil triflato (2) e difenil disseleneto $(\mathbf{5 0})$ na presença de CsF

A reação delineada no Esquema 21 leva à formação de calcogenetos que podem encontrar aplicação como ligantes em química de coordenação.

No curso das pesquisas de Yoshida e colaboradores acerca de reações de inserção de arinos em ligações sigma, a reação entre 2-(trimetilsilil)aril triflatos (2) e acilfluorenos (52) na presença de KF e éter 18-coroa-6, conduziu à formação de produtos de acilfluorenilação de arinos $(\mathbf{5 3})$ em rendimentos que variaram de moderados a excelentes ${ }^{29}$ (Esquema 22).

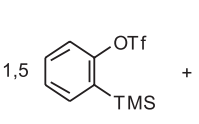

2

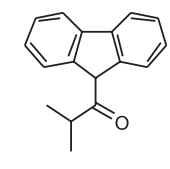

52
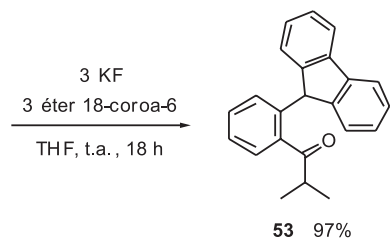

$5397 \%$
Esquema 22. Síntese do produto de acilfluorenilação do benzino 53 por reação entre 2-(trimetilsilil)fenil triflato (2) e 9-fluorenil isopropil cetona (52) na presença de KF e éter 18-coroa-6

Pela transformação apresentada no Esquema 22 temos um exemplo do potencial da reação de inserção de arinos a ligações C-C, com a formação de compostos aromáticos que seriam dificilmente obtidos em uma única etapa reacional por outras metodologias sintéticas. ${ }^{29}$

A reação de inserção de arinos em ligações sigma carbono-metal (C-M) de reagentes organometálicos, pode ser virtualmente exemplificada pelo trabalho de Zhang e colaboradores, que envolve a reação entre sililaril triflatos (2) e alcinos terminais (54) na presença de $\mathrm{CuI}$ e CsF, considerando essencialmente a formação in situ de acetiletos de cobre (I), ${ }^{30}$ resultando no isolamento de alcinos dissubstituídos $(\mathbf{5 5})^{31}$ (Esquema 23).
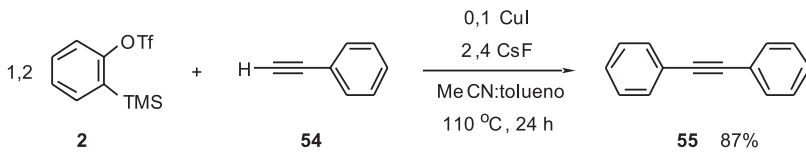

Esquema 23. Síntese de difenilacetileno (55) por reação entre 2-(trimetilsilil) fenil triflato (2) e fenilacetileno (54) na presença de CuI e CsF

A reação de inserção de acetileto de cobre (I) em benzino delineada no Esquema 23 pode ser extrapolada para a transformação multicomponente entre precursores de arinos (56), alcinos terminais (57) e cloretos de alila (58), no entanto, além de $\mathrm{CuI} \mathrm{e} \mathrm{CsF,} \mathrm{uma} \mathrm{fosfina}$ bidentada (dppe) e uma base $\left(\mathrm{K}_{2} \mathrm{CO}_{3}\right)$ foram empregadas, resultando em eninos aromáticos (59) ${ }^{31}$ (Esquema 24).

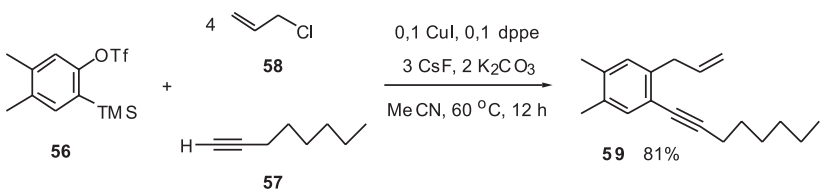

Esquema 24. Síntese do enino aromático 59 por reação entre o sililaril triflato 56, 1-octino (57) e cloreto de alila (58) na presença de $\mathrm{CuI}, \mathrm{CsF}$, dppe e $\mathrm{K}_{2} \mathrm{CO}_{3}$

As reações mostradas nos Esquemas 23 e 24 podem exemplificar, considerando a formação de acetiletos de cobre (I) no meio reacional, ${ }^{30} \mathrm{a}$ inserção de arinos em ligações C-M de reagentes organometálicos. ${ }^{31}$ Este pressuposto foi reforçado por resultados recentemente publicados por Yoshida e colaboradores. ${ }^{32}$

Larock e colaborador estudaram extensivamente reações de $N$ arilação de aminas e sulfonamidas, bem como reações de $O$-arilação de fenóis e ácidos arilcarboxilílicos, as quais podem ser formalmente consideradas como reações de inserção de arinos em ligações sigma heteroátomo-hidrogênio (Het-H) $)^{33-35}$ (Esquemas 25 a 28).

Inicialmente, sililaril triflatos (2) foram submetidos à reação com aminas $(\mathbf{6 0})$ resultando em arilaminas $(\mathbf{6 1})$ em ótimos rendimentos..$^{33,35}$ (Esquema 25)

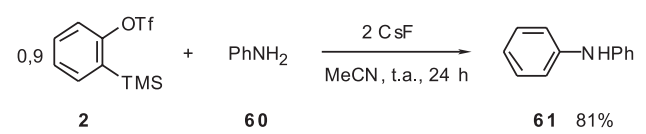

Esquema 25. Síntese da $N, N$-difenilamina (61) por reação entre 2-(trimetilsilil)fenil triflato (2) e anilina (60) na presença de CsF

Com relação à reação delineada no Esquema 25, vale mencionar que quando excesso do precursor de benzino 2 é utilizado, trifenilamina é produzida em excelente rendimento isolado. ${ }^{33,35}$

Quando sulfonamidas (62) são deixadas reagir com precursores de arinos (2) na presença de CsF, diarilsulfonamidas (63) são obtidas em rendimentos excelentes. ${ }^{33,35}$ (Esquema 26)

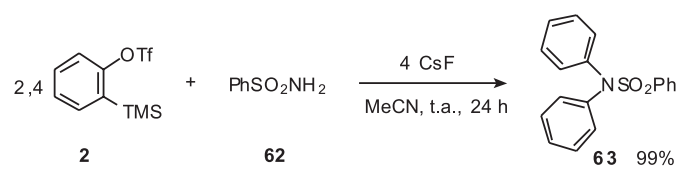

Esquema 26. Síntese da $\mathrm{N}, \mathrm{N}$-difenilbenzenossulfonamida (63) por reação entre 2-(trimetilsilil)fenil triflato (2) e benzenosulfonamida (62) na presença de $C s F$

Vale destacar que a síntese de $\mathrm{N}$-arilsulfonamidas ( $\mathrm{RSO}_{2} \mathrm{NHAr}$ ) a partir de sulfonamidas primárias $\left(\mathrm{RSO}_{2} \mathrm{NH}_{2}\right)$ não foi possível pelo processo apresentado no Esquema 26. ${ }^{33,35}$ Posteriormente, sililaril triflatos (2) foram submetidos à reação com fenóis (64) resultando em diariléteres (65) em ótimos rendimentos. ${ }^{34,35}$ (Esquema 27)

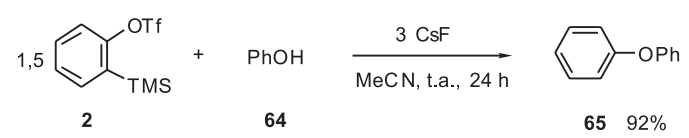

Esquema 27. Síntese de difeniléter (65) por reação entre 2-(trimetilsilil)fenil triflato (2) e fenol (64) na presença de CsF

A reação delineada no Esquema 27 ocorre sob condições reacionais brandas, sendo compatível com uma variedade de grupos funcionais. ${ }^{34,35}$

Da mesma maneira que fenóis, quando ácidos arilcarboxílicos (66) são deixados reagir com precursores de $\operatorname{arinos}(\mathbf{2})$ na presença de 
CsF, ésteres diarílicos (67) são formados em ótimos rendimentos. ${ }^{34,35}$ (Esquema 28)
2

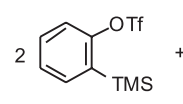

$\mathrm{PhCOOH}$

66

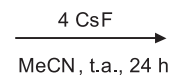

$6781 \%$

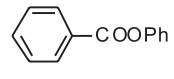

Esquema 28. Síntese do benzoato de fenila (67) por reação entre 2-(trimetilsilil)fenil triflato (2) e ácido benzóico (66) na presença de CsF

A reação delineada no Esquema 28 também ocorre sob condições reacionais brandas, sendo compatível com uma variedade de grupos funcionais. . $^{34,35}$

Ainda com relação às reações apresentadas nos Esquemas 25 a 28 não podemos deixar de destacar que todas elas podem ser realizadas na ausência de metais de transição. ${ }^{33-35}$

\section{REAÇÕES DE INSERÇÃO DE ARINOS A LIGAÇÕES SIGMA CATALISADAS POR PALÁDIO}

O primeiro manuscrito usando arinos em reações de inserção em ligações sigma na presença de catalisador de paládio foi publicado por Shirakawa, Hiyama e colaboradores. ${ }^{10}$ Em tal manuscrito os arinos gerados a partir de 2-(trimetilsilil)aril triflatos (2) na presença de $\mathrm{CsF}$, inseriram na ligação C-Sn de alquinil e vinil estananas (68) na presença de quantidade catalítica de complexo de paládio, resultando em aril estananas 2-substituídas (69) em rendimentos modestos. ${ }^{10}$ (Esquema 29).

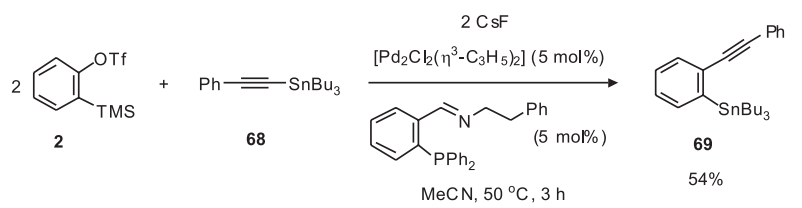

Esquema 29. Síntese da tributil[2-(feniletinil)fenil]estanana (69) por reação entre 2-(trimetilsilil)fenil triflato (2) e tributil(feniletinil)estanana (68) na presença de CsF e paládio

A aplicabilidade sintética dos produtos da reação apresentada no Esquema 29 foi avaliada usando a tributil[2-(feniletinil)fenil] estanana (69) na síntese de diversos compostos aromáticos (70-72), produzidos por reações de acoplamento cruzado (70 e 71) e por reações de transmetalação/adição à carbonila (72), fazendo uso de condições reacionais descritas na literatura. ${ }^{10}$ (Esquema 30).

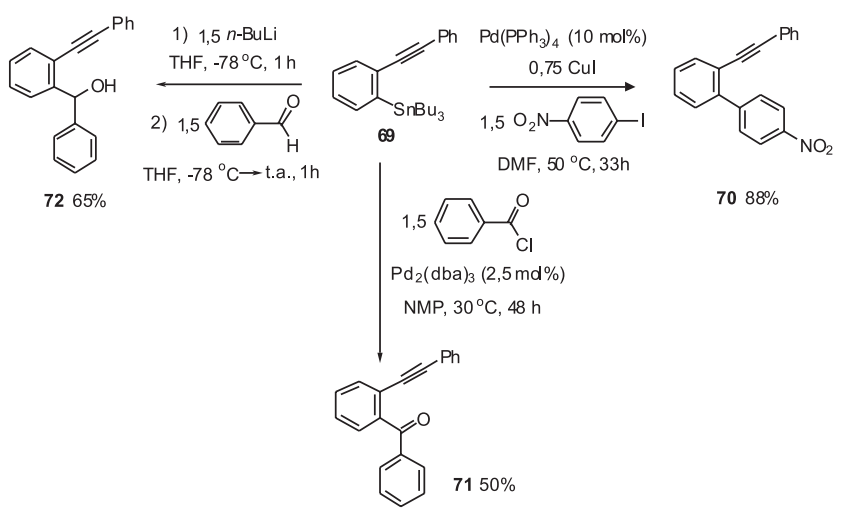

Esquema 30. Síntese dos compostos aromáticos (70-72) fazendo uso da tributil[2-(feniletinil)fenil]estanana (69), por meio de reações de acoplamento cruzado $(\mathbf{7 0}$ e 71) e reações de transmetalação/adição à carbonila (72)
Posteriormente, Yoshida, Kunai e colaboradores publicaram trabalho envolvendo a reação de inserção de arinos formados a partir de sililaril triflatos (2) e KF/éter 18-coroa-6, em ligação sigma Si-Si de dissilanos cíclicos (73), na presença de quantidade catalítica de paládio, resultando na produção de compostos carbocíclicos dissililados (74). ${ }^{36,37}$ (Esquema 31).

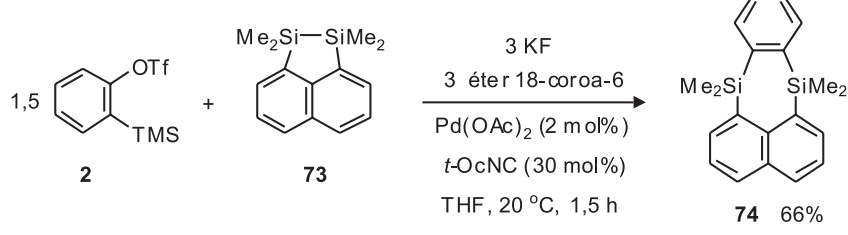

Esquema 31. Síntese do carbocíclico dissililado 74 por reação entre 2-(trimetilsilil)fenil triflato (2) e o dissilano cíclico 73 na presença de KF/éter 18-coroa-6 e paládio

Yoshida, Kunai e colaboradores, dando continuidade às suas pesquisas envolvendo reações de inserção de arinos a ligações sigma, implementaram a reação de inserção de arinos formados a partir de sililaril triflatos (2) na presença de KF/éter 18-coroa-6, em ligações sigma Sn-Sn de diestananas (75), fazendo uso de paládio em quantidade catalítica, resultando na produção de 1,2-bis(trialquilestanil) benzenos (76). ${ }^{38}$ (Esquema 32$)$

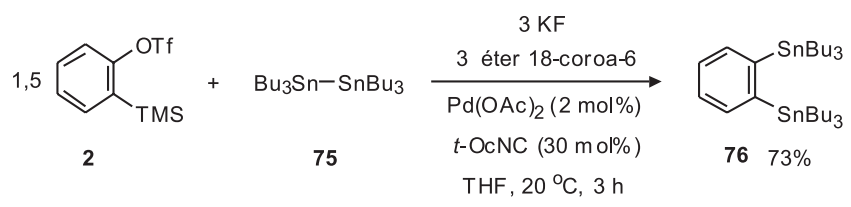

Esquema 32. Síntese do 1,2-bis(tributilestanil)benzeno (76) por reação entre 2-(trimetilsilil)fenil triflato (2) e hexabutildiestanana (75) na presença de $\mathrm{KF}$ / éter 18-coroa-6 e paládio

Explorando a reação de diestanilação de arinos apresentada no Esquema 32, Yoshida, Kunai e colaboradores desenvolveram uma metodologia sintética para a dimerização-diestanilação de arinos catalisada por paládio, deixando a diestanana 77 reagir com o sililaril triflato 2 na presença de KF/éter 18-coroa-6 e do sistema catalítico $\mathrm{Pd}(\mathrm{OAc})_{2} / \mathrm{ETPO}^{39}$ (Esquema 33).

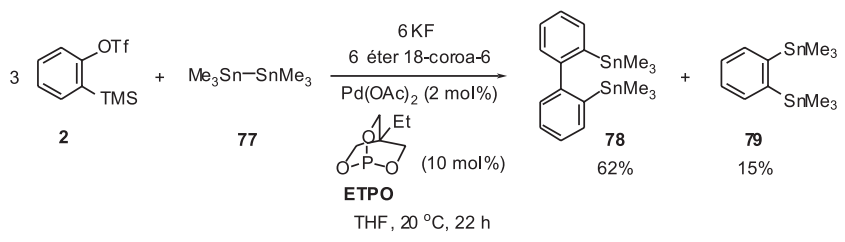

Esquema 33. Síntese do 2,2'-bis(trimetilestanil)bifenil (78) e do 1,2-bis(trimetilestanil)benzeno (79) por reação entre 2-(trimetilsilil)fenil triflato (2) e a hexametildiestanana (77) na presença de KF/éter 18-coroa-6 e $\mathrm{Pd}(\mathrm{OAc})_{2} / \mathrm{ETPO}$

Vale destacar que o sucesso da reação delineada no Esquema 33, que leva à formação preferencial do produto de dimerizaçãodiestanilação 78, foi governado essencialmente pela natureza do ligante empregado na transformação. ${ }^{39}$

O potencial sintético dos produtos de dimerização-diestanilação (Esquema 33), foi avaliado empregando o composto 78 na síntese de diversos sistemas biarílicos $(\mathbf{8 0 - 8 3})$, produzidos por reações conhecidas. ${ }^{39}$ (Esquema 34). 


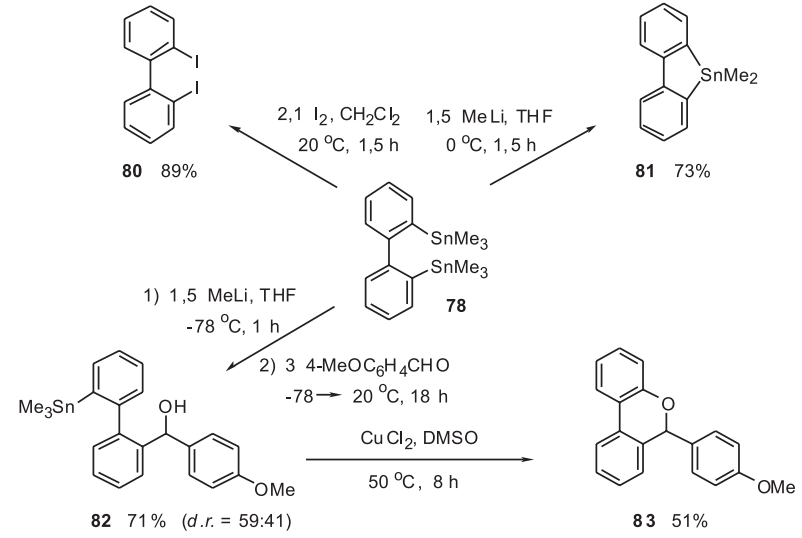

Esquema 34. Síntese dos compostos biarílicos (80-83) fazendo uso do 2,2'-bis(trimetilestanil)bifenil (78)

\section{CONCLUSÕES}

Voltando nossa atenção para o ressurgimento da química de benzino, que está sendo orquestrado pelo emprego de sililaril triflatos na formação de arinos sob condições reacionais brandas, reunimos neste manuscrito trabalhos que ilustram a importância de benzino e seus derivados, gerados pela reação entre 2-(trimetilsilil)aril triflatos e íons fluoreto, em reações de inserção em substratos contendo uma porção nucleofílica e outra eletrofílica, separadas por uma ligação sigma. Adicionalmente, procuramos destacar a importância e a versatilidade de tais transformações na preparação de sistemas aromáticos altamente funcionalizados, tendo em vista a grande dificuldade de produzir tais compostos em apenas uma etapa reacional por outros métodos sintéticos.

\section{AGRADECIMENTOS}

Ao Conselho Nacional de Desenvolvimento Científico e Tecnológico (CNPq) e à Fundação de Apoio ao Desenvolvimento do Ensino, Ciência e Tecnologia do Estado do Mato Grosso do Sul (FUNDECT) pelo apoio financeiro.

\section{REFERENCIAS}

1. Pellissier, H.; Santelli, M.; Tetrahedron 2003, 59, 701; Hart, H. Em The Chemistry of Triple-Bonded Functional Groups, Supplement C2; Patai, S., ed.; Wiley: Chichester, 1994, cap. 18; Gilchrist, T. L. Em The Chemistry of Functional Groups, Supplement C; Patai, S.; Rappoport, Z., eds.; Wiley: Chichester, 1983, cap. 11; Hoffmann, R. W.; Dehydrobenzene and Cycloalkynes, Academic Press: New York, 1967.

2. Logullo, F. M.; Seitz, A. H.; Friedman, L.; Organic Synthesis, Coll. Vol. 5, Willey: New York, 1973, p. 54; Stiles, M.; Miller, R. G.; Burckhardt, U.; J. Am. Chem. Soc. 1963, 85, 1792.

3. Fieser, L. F.; Haddadin, M. J.; Organic Synthesis, Coll. Vol. 5, Willey: New York, 1973, p. 1037; Le Goff, E.; J. Am. Chem. Soc. 1962, 84, 3786.

4. Wittig, G.; Organic Synthesis, Coll. Vol. 4, Willey: New York, 1963, p. 964; Wittig, G.; Erhard, K.; Chem. Ber. 1958, 91, 895.

5. Lin, W.; Chen, L.; Knochel, P.; Tetrahedron 2007, 63, 2787; Lin, W.; Ilgen, F.; Knochel, P.; Tetrahedron Lett. 2006, 47, 1941.

6. Campbell, C. D.; Rees, C. W.; J. Chem. Soc. (C), 1969, 752.; Campbell, C. D.; Rees, C. W.; J. Chem. Soc. (C), 1969, 748; Campbell, C. D.; Rees, C. W.; J. Chem. Soc. (C), 1969, 742.
7. Himeshima, Y.; Sonoda, T.; Kobayashi, H.; Chem. Lett. 1983, 1211.

8. Cobas, A.; Guitián, E.; Castedo, L.; J. Org. Chem. 1997, 62, 4896.

9. Peña, D.; Escudero, S.; Pérez, D.; Guitián, E.; Castedo, L.; Angew. Chem., Int. Ed. 1998, 37, 2659. Para uma revisão sobre o assunto: Guitián, E.; Pérez, D.; Peña, D.; Top. Organomet. Chem. 2005, 14, 109.

10. Yoshida, H.; Honda, Y.; Shirakawa, E.; Hiyama, T.; Chem. Commun. 2001, 1880 .

11. Yoshida, H.; Shirakawa, E.; Honda, Y.; Hiyama, T.; Angew. Chem., Int Ed. 2002, 41, 3247.

12. Peña, D.; Iglesias, B.; Quintana, I.; Pérez, D.; Guitián, E.; Castedo, L.; Pure Appl. Chem. 2006, 78, 451; Peña, D.; Cobas, A.; Pérez, D.; Guitián, E.; Synthesis 2002, 1454.

13. Peña, D.; Pérez, D.; Guitián, E.; Angew. Chem., Int. Ed. 2006, 45, 3579.

14. Yoshida, H.; Fukushima, H.; Morishita, T.; Ohshita, J.; Kunai, A.; Tetrahedron 2007, 63, 4793; Yoshida, H.; Fukushima, H.; Ohshima, J.; Kunai, A.; Angew. Chem., Int. Ed. 2004, 43, 3935; Yoshida, H.; Fukushima, H.; Ohshita, J.; Kunai, A.; Tetrahedron Lett. 2004, 45, 8659.

15. Yoshida, H.; Terayama, T.; Ohshita, J.; Kunai, A.; Chem. Commun. 2004, 1980.

16. Yoshida, H.; Minabe, T.; Ohshita, J.; Kunai, A.; Chem. Commun. 2005, 3454.

17. Tambar, U. K.; Stoltz, B. M.; J. Am. Chem. Soc. 2005, 127, 5340.

18. Tambar, U. K.; Ebner, D. C.; Stoltz, B. M.; J. Am. Chem. Soc. 2006, 128, 11752 .

19. Yoshida, H.; Watanabe, M.; Ohshita, J.; Kunai, A.; Chem. Commun. 2005, 3292 .

20. Yoshida, H.; Watanabe, M.; Ohshita, J.; Kunai, A.; Tetrahedron Lett. 2005, 46, 6729.

21. Yoshida, H.; Watanabe, M.; Ohshita, J.; Kunai, A.; Chem. Lett. 2005, 34, 1538.

22. Liu, Z.; Larock, R. C.; J. Am. Chem. Soc. 2005, 127, 13112.

23. Huang, X.; Xue, J.; J. Org. Chem. 2007, 72, 3965.

24. Xue, J.; Wu, L. L.; Huang, X.; Chin. Chem. Lett. 2008, 19, 631.

25. Ni, C.; Zhang, L.; Hu, J.; J. Org. Chem. 2008, 73, 5699.

26. Beltrán-Rodil, S.; Peña, D.; Guitián, E.; Synlett 2007, 1308.

27. Yoshida, H.; Mimura, Y.; Ohshita, J.; Kunai, A.; Chem. Commun. 2007, 2405.

28. Toledo, F. T.; Marques, H.; Comasseto, J. V.; Raminelli, C.; Tetrahedron Lett. 2007, 48, 8125.

29. Yoshida, H.; Kishida, T.; Watanabe, M.; Ohshita, J.; Chem. Commun. 2008, 5963.

30. Raminelli, C.; Prechtl, M. H. G.; Santos, L. S.; Eberlin, M. N.; Comasseto, J. V.; Organometallics 2004, 23, 3990; Sonogashira, K.; Tohda, Y.; Hagihara, N.; Tetrahedron Lett. 1975, 50, 4467; Stephens, R. D.; Castro, C. E.; J. Org. Chem. 1963, 28, 2161; Stephens, R. D.; Castro, C. E.; J. Org. Chem. 1963, 28, 3313.

31. Xie, C.; Liu, L.; Zhang, Y.; Xu, P.; Org. Lett. 2008, 10, 2393.

32. Yoshida, H.; Morishita, T.; Nakata, H.; Ohshita, J.; Org. Lett. 2009, 11, 373.

33. Liu, Z.; Larock, R. C.; Org. Lett. 2003, 5, 4673.

34. Liu, Z.; Larock, R. C.; Org. Lett. 2004, 6, 99.

35. Liu, Z.; Larock, R. C.; J. Org. Chem. 2006, 71, 3198.

36. Yoshida, H.; Ikadai, J.; Shudo, M.; Ohshita, J.; Kunai, A.; J. Am. Chem. Soc. 2003, 125, 6638

37. Yoshida, H.; Ikadai, J.; Shudo, M.; Ohshita, J.; Kunai, A.; Organometallics 2005, 24, 156.

38. Yoshida, H.; Tanino, K.; Ohshita, J.; Kunai, A.; Angew. Chem., Int. Ed. 2004, 43, 5052.

39. Yoshida, H.; Tanino, K.; Ohshita, J.; Kunai, A.; Chem. Commun. 2005, 5678. 